\title{
PHYSIOLOGICAL AND IMMUNE PATHWAY RESPONSES OF RAINBOW TROUT JUVENILES TO DIETARY SUPPLEMENTATION WITH INULIN AND LACTOFERRIN
}

\author{
Trinh Dinh Khuyen ${ }^{1}$, Syaghalirwa.N.M. Mandiki ${ }^{1}$, Jessica Douxfils ${ }^{1}$, Valérie Cornet ${ }^{1}$, Peter De \\ Schryver ${ }^{2}$, Peter Bossier ${ }^{2}$, Stéphane Betoulle ${ }^{3}$, Lluis Tort ${ }^{4}$ and Patrick Kestemont ${ }^{1 \S}$ \\ ${ }^{I}$ Research Unit in Environmental and Evolutionary Biology (UBRE), University of Namur (FUNDP), \\ Rue de Bruxelles 61, 5000 Namur, Belgium \\ ${ }^{2}$ Laboratory of Aquaculture \& Artemia Reference Center (ARC), Ghent University, Rozier 44, B-9000 \\ Gent, Belgium
}

${ }^{3}$ Laboratory of UMR-I 02 Stress Environnementaux et Biosurveillance des Milieux Aquatiques, University of Reims Champagne-Ardenne Campus Moulin de la Housse, BP 1039, FR-51687 Reims Cedex 2, France

${ }^{4}$ Department of Cell Biology, Physiology and Immunology, Universitat Autònoma de Barcelona, 08193 Bellaterra, Spain

\begin{abstract}
The objectives of this study were to determine the ability of lactoferrin and inulin (low dose: $0.1 \%$ vs high dose: $1 \%$ diet) for improving the immune status and disease resistance of trout juveniles and to characterize the physiological and immune pathways by analysing different biological endpoints, including immune gene expressions, humoral immune parameters, blood leukocyte populations and gut microbial diversity.

After 51 days of treatment, there was a highly significant difference of spleen respiratory burst activity of total leukocyte cells or total granulocyte cells in fish fed inulin at $0.1 \%$ of the diet compared to those of the control and other treatments. There was a dose-dependent increase for blood neutrophil cells on day 51, especially for lactoferrin while a significant increase of blood monocyte cells was observed in all treated fish whatever the compound and the dose.
\end{abstract}

Dietary inulin at $0.1 \%$ and lactoferrin at $1 \%$ induced the highest bacterial resistance ability of rainbow trout during 14 days. The highest survival rate of rainbow trout after bacterial infection $\left(3.1 \times 10^{7}\right.$ CFU/100 g of fish) was recorded in inulin $0.1 \%$ (48\%), followed by lactoferrin $1 \%$ and lactoferrin $0.1 \%$ (38\% and $36 \%$, respectively). Meanwhile, the survival of control fish averaged $19 \%$ and fish fed inulin $1 \%$ diet was $7 \%$. Plasma lysozyme values did not significant differ among treatments during the dietary test. But, there was significant increase of lysozyme level in lactoferrin $1 \%$ compared with those of the control after $44 \mathrm{~h}$ of bacteria injection.

On day 35, total immunoglobulin (Ig) content in plasma increased in all treatments and doses, except for inulin $0.1 \%$. On day 51 , there were significantly higher Ig levels for low doses compared to control and high doses of all treatments. Forty four $\mathrm{h}$ after bacterial injection, the total Ig of all treatments rapidly decreased but remained significant higher in fish fed inulin $0.1 \%$, lactoferrin $0.1 \%$ and lactoferrin $1 \%$ compared to control and inulin $1 \%$.

In general, inulin $0.1 \%$ and lactoferrin $1 \%$ diet fed to rainbow trout juveniles during 51 days can modify the leukocyte proportions, significantly improve the respiratory burst activity of macrophage cells, and increase the amount of $\mathrm{Ig}$ as well as the resistance of fish to stress infection. Other endpoints, such as alternative complement pathway hemolytic activity; IgM content, gut microbial diversity and immune gene expressions are still under analysis.

\section{KEYWORDS}

Inulin; lactoferrin; immunity; rainbow trout (Oncorhynchus mykiss); juveniles 
${ }^{\S}$ Corresponding author. Tel.: +3281724363; Fax: +3281724362

E-mail address: patrick.kestemont@unamur.be 